\title{
Research of the Development Path of Sports New Media under the Visual Threshold of Game's Copyright
}

\author{
Wu Zhong \\ Physical Education School \\ Wuhan Business University, Wuhan \\ Wuhan, China \\ 7849800@qq.com
}

\begin{abstract}
From the perspective of game's copyright, by the method of documentation, data analysis, interview on experts and logical analysis, the paper expounds the current situation of the development of sports new media, explores the symbiotic relationship between the game's copyright and the sports new media, makes an outlook on the development road of the profit innovation of spots' new media and puts forward relevant suggestions and countermeasures: to form good communication environment interacting with traditional media, to transform the broadcasting right to copyright and to accelerate the transformation of new sports media material technology and social initiative to widely attract audience and crack down on piracy learning from developing experience of foreign new media.
\end{abstract}

Keywords—sports game; games' copyright; new media; development path

\section{INTRODUCTION}

Environment of domestic sports industry and sports media improves greatly in recent years, several sports new media headed by Letv sports and Tencent sports infrequently make blockbuster investments on kinds of copyrights of all sports games to constantly expand their copyright maps, with cost by an annual growth rate of more than three times. At the same time, the two major topics of "how to operate the copyright in hand" and "how to make a profit on the copyright by the buyers" form unavoidable hotpots in educational and industrial circles as well as the key to the development of the sports new media. However in recent years, there are few domestic literatures in respect thereof.

Under the visual threshold of the copyright of sports game, the profit innovation of sports new media becomes very important. The key point of achievement between the game's copyright and the new media is that how to use sports emerging power to bring new vitality to the game's copyright in order to make the value of the sports game continue to rise. The constant majorization of the physical forms and contents of the new media as well as the constant enhancement of the value of sports game's copyright is not only reflected in the discussion of the symbiotic relationship between the game's copyright and the sports new media, but also in the analysis of theoretical and practical significance on the sustainable development path of Chinese sports industry.

\section{The Development Condition of Sports New MediA UNDER THE VISUAL THRESHOLD OF GAME'S COPYRIGHT}

\section{A. The Development Characteristic of the Sports New Media}

New media refers to the network media gradually matured after the creation of the television media, and the mobile media with the core of mobile communication technology which also includes medias such as digital television, network television etc. integrated with a variety of media technology. In the emerging field of "new media" in Journalism and Communication, the concept of sports new media undoubtedly pushes the word "new" to a new height. Sports new media, as an important part of mass media, provides a powerful driving force for the sports media entering the competition era of scale, diversification and internationalization. At present, the sports new media mainly has the features that:

- Attracting a wide audience by the advantage of speech, full scale and large quantity. On the sports field with every minute counting and rapidly changing, the new media, with its unique advantages, presents advantage of speedy transmission with full methods, containing more content to attract a wide audience. The participation of multiple media platform makes the public change from passive recipients in a single transmission to transmitters with subjective initiative. The emergence of the information resources in high frequency and high strength has basically met the audience's entertainment and mental psychology. Through social media, mobile terminal linkage, using the network technology, it realizes the notification in all directions through a full platform and across the terminals beyond the handicap of the traditional transmission to make sports new media achieve advantages on live experience and users' coverage.

- Wide game's resources with sharper market competition. Although the IP business value of domestic games has not been fully and effectively developed, the domestic sports, under the support of policy, exceed over thousand a year, whose resource gives more opportunities to the sports media company [1]. The Television still stays at the dominant position, but its 
time conflict, the broadcast content and the single direction of propagation becomes a hard wound. The new media rides up with strong interactivity, timeliness and portability to quickly occupy the market. The sports media companies which lock in advantage the dominant resources have more market dominances. The sharper marketization competition of domestic sports new media has become a great historical opportunity of the marketization of domestic sports system.

- An oligopoly pattern is formed in the good policy environment. In recent years, our country's relevant sports industry reforming plans are continuously launched, making it clear to "ease restrictions on competition rights" which undoubtedly is good to the sports new media market and other participants in China. At present, the pattern that the sports new media industry capital in our country helps the oligopoly has been initially formed, when several leading enterprises are competing for resources of sports game's copyright and attempt to build sports media ecology industry chain gradually. For example, Letv sports [2], which was formally established in March 2014, chose to begin from the upstream of the industrial chain, bought the copyright in a large number, homemade IP marketing strategies and used the intellectualization of game's operation and value-added sports' service to attract users. Tencent sports adopted to locate the media platform and focus on the operation of community marketing strategy so as to seize the top matches' copyright through deep ploughing and careful management from the upstream to downstream.

\section{B. The Development Condition of Sports New Media Under the Visual Threshold of Game's Copyright}

Sports media industry is formed by three links of the upper, the medium, the bottom of which media is in the medium link, while game's copyright is the source of the upper link. To reflect more values in sports industry, the media has to as far as possible approach the upper resources. As the opening of rights of the game's broadcast, it is conducive to a series of revenue exploitations of sports game if various main parts jointly participate in market competition and positively fight for the game's copyright, which makes the sports products at a reasonable market price. Letv sports announced in May 2015 to get 800 million in the first round capital which was valued at 2.8 billion RMB. As the sports company with the highest valuation in China, it reflects a vast space in Chinese sports copyright market [3].

- The new form of sports market brought by the game copyright. The game's copyright resources with high quality surely promote the sports market competition, and break the original media landscape with copyright value increasing dramatically. The domestic income changes of the top competition copyright resources such as the Chinese super league, the NBA and the Spanish reflect a high development value of the game's copyright in the market competition. With the crazy enlargement of the copyright resources, the sales amount of Letv super sports membership reached 330 million RMB on April 14 2016, and the daily total sales amount of Letv members reached 2.02 billion RMB. The hot sale of membership makes all Letv sports ecological products sold well which are the direct benefit to the new media from game's copyright. One of the reasons that the game's copyright becomes the competitive focus is the scarcity thereof. As the source of the sports media industry, its way to be cashed varies a lot by forming into all kinds of sports consumption such as broadcast, sponsorship, tickets and the derivatives. Its users are of good bases with huge cluster benefit and active paying consciousness. The athletic game shows have strong antagonism with uncertainty which makes the games with extremely high ornamental value and accumulated a unique game culture. The scarcity of the games with high quality is also reflected in the few number of the top athletes, long period of breeding, limited categories of games and high threshold in respect thereof. The series of potential values have given rise to industries of expanding users' number, enhancing brand strength, strengthening the post-production, promoting innovation and technical ability. For sports new media, it makes overlap between copyright and its own technology with a splendid spreading effect. The high development value of the game's copyright is constantly providing impetus for the sports new media to move forward [4].

- The current industry status of game's copyright provides condition of cooperation and win-win for both. From policy level, "several opinions on speeding up the development of sports industry, and promoting the sports consumption" in 2014 stated that the future sports industry would be introduced by market-oriented means, simplifying administration and expanding the scale of sports market. " the overall concept of the reform and development of football in China " in 2015 also clearly stated to innovate the way to coverage football games and to popularize the operation way, in order to explore the practical forms of development of the traditional media integrated with new media in the field of football and to increase the income of new media market. From the economic level, the statistics data of national bureau shows that products and service consumption of residents' recreation, education and culture rises by $1.4 \%$, with residents' consumption level improving and the entertainment demand growing. From cultural level, the authorization process of domestic game is more and more normalized, and the law and public copyright consciousness is improved. From the technical level, with the popularization of the internet technology, the proportion of online media in live sports games has soared, and the optimization of VR, AR, 3D technology can ensure that the audience's watching and interactive experience [5]. In general, the present situation of the game's copyright industry is overall positive.

- The sports new media adds the value of game's copyright. The importance of sports media to the game's copyright is not only reflected in the fact that media is the communication channel of game, but also in the fact 
that the media can promote the establishment of the construction of the game's big ecosystem [6]. Media can not only promote the improvement of the standards of the appearance of the game's content and products and the production level, but also can dig the story behind the game, enhance the audience's emotion, make the audience no longer "tourists" so as to provide a large number of high-quality viewers for the game. Of course, in addition to the video resources, new media can realtimely render the game data, analysis the tactics and implement the cross-border cooperation of sports and entertainment. PC and mobile end brings a rich users' experience for the game, which gives the game more opportunities to build fans' culture and makes the game to be cashed. On the other hand, revaluation of the copyright cost and the introduction of capital will greatly improve the revenue of all Chinese super clubs, which provides assistance in and out for the club. In the future, in order to improve the competitive level and market awareness of the club, the market in which players are transferred to members will continue to be hot, the game's attraction will rise sharply, and the operators will also produce program with high quality in a high level under the pressure of high cost and wide attention.

\section{The Development Problems of Sports New Media}

\section{A. The Exclusive Statue of Traditional Media Which is Difficult to Be Shaken}

Although the copyright war of sports new media is escalating and the professional setups of major sports media companies are also greatly increasing, the exclusive statue of traditional media represented by television, with its great credibility, historical advantages, and the protection of national policy is difficult to be shaken in a long time. In year 2015, the proportion of TV sports programs in the whole TV market was $4 \%$, of which the sports broadcast was $2.52 \%$ with a good effect, and the overall resource utilization rate is $37 \%$, at the third position in other programs [7]. During the competition of sports channel, with the advantages of copyright, CCTV is in the absolute advantage position, with the broadcast proportion of $17 \%$ and the ratings proportion of $66 \%$, of which the copyright advantage is obvious. With this phenomenon, it is easy to prevent the game's sales party from bargaining, makes the copyright value difficult to be improved and also proposes challenges for the development of the sports new media's copyright.

\section{B. Lack of Credibility, Rigor and Profundity}

Since sports industry in China started late with inadequate resource flow, it has not formed a system of operating mechanism, and it lacks of sports media companies with specialized service ability. At present most media company involving in sports are still in the early stage of development, with little professional quality and gene which has a big gap comparing with the ultimate goal of industrial resources platform. On the other hand, the sports new media sometimes has an excessive pursuit of timeliness and information fragmentization, where errors of the content easily occur and the transmission quality is discounted to a certain extent. The excessive pursuit of business and entertainment for the media to cater to the audience is also a problem worth thinking about.

\section{Material Technology and Social Activism Still Not High}

On the one hand, the device properties of the network media company to broadcast games or to interact with audience need to be strengthened, and the problems of image quality and stucking are to be solved. On the other hand feeling and the audience's scale and quality need to be improved. With the fragmentation of information, the audience's attention and influence also appears the phenomenon of polarization and fragmentation. Focusing on the title or on the interesting point only becomes a normal case for a number of audiences to watch games through new media. The audience's loyalty of the sports game directly decides if the future payment model of new media game can be opened or not. And, Chinese audiences have been used to the long free time of sports with weak paying consciousness.

\section{The Serious Problem of Piracy}

Since the sports' copyrights cost hikes, the live broadcast market is easy to be coveted by some Internet lives with low cost. Regular sports medias are facing a smokeless war with pirates when provides with original broadcast. The protections in law of intellectual property of traditional media has not been perfect, and the definition that it is whether a property right or an intellectual property of sports game which is infringed by illegal Internet lives is not clear, which makes the new medias difficult to protect their own rights. On the other hand, on some large social platforms, the publication of small video clips and contents of the fans' reaction and of the behind-the-scenes footage also brings disputes on the copyright.

\section{The Development Path of Sports New Media Under THE VISUAL THRESHOLD OF GAME'S COPYRIGHT}

\section{A. Interacting With Traditional Media to Form a Good Communication Environment}

New media and traditional media have its own advantages, so it is particularly important to form a good communication environment with integration between both of them. It shall take advantage of the traditional media to improve the digital technology, to make the transmission resources enriched and to take a preemptive opportunity in respects of the content production and brand spreading. It will bring the comprehensive operation of the game's copyright resources with much convenience by using new media network technology, integrating with communication means for live transmission to ensure a speed high speed and the globalization thereof.

\section{B. Learning from Developing Experience of Foreign New Media to Turn the Broadcasting Right to a Copyright}

Sports new media industry in China is still in a infancy period, with limited experience and professional quality which can learn from the developing mode from mature sports media 
abroad. Domestic sports new media shall strengthen the resources and comply with the trend of media to make the mobile end clear.

Web portals in early time portal open the information age, and a batch of sports channel represented by Sina, Sohu, Tencent as the earliest transmission window for sports information which trains the first batch of users. With the advent of mobile Internet, industries of search, video, and ecommerce are accelerating migration from PC to mobile end, of which the current flow and income of mobile end are almost the same with or even obviously more than that of PC end. But sports new media is still on the way of transition, while the mobile end user has not formed a scale. Mobile applications give priority to exercise and sports, of which the permeability of sports live programs is less than $50 \%$. In the future, it is the only way for the sports new media to turn the broadcasting right to a copyright and to make the content in late period more attractive.

\section{Speeding up the Reform of Sports New Material Technology and Social Media Initiative}

For sports new media, our country is still in the infancy, it is the only way to accelerate the sports new material technology, to strengthen hardware and software, to absorb professional sports media talents, and to explore relevant functions. The improvement of all values of the copyright and the new media are based on the quality and quantity of the audience; therefore it is the key point of aiming at the users' requirements, improving the permeability and stimulating the participant sense to release the value of copyright. For sports stars' fans, it is needed to focus on development of the surroundings of the stars, the production of stars' products and their derivatives. In respect of favors on the games, it needs to make well-made media products, to capture with high-end video technology in various aspects, to make professional postproduction and real-time explanation. For audience with strong national pride, it needs to strengthen their participant sense, to make professional featured programmes to realize crossplatform interactions. In addition, it shall consider the specific conditions with more details such as the gender ratio, the age structure, the career structure, and the income structure of audience. Seeing from the data, the mobile sports users are mainly men and young people with average income level, who are mostly engaged in careers with relatively abundant private time.

\section{Cracking Down on Piracy}

Standing on the view of sports right party, the copyright protection of sports games is an important task to respect the investment of the copyright owners and to maintain a justified sports market. The sports industry and culture industry are copyright industries. Since the price of the sports copyright is too high, it will be impossible to talk about the added value of sports industry if the copyright has not been strictly protected. Nowadays, piracy is a very headache problem whether for a large traditional media such as CCTV, or for a mature sports new media such as ESPN. Therefore, not only the copyright protection of sports games needs the collaboration among copyright owners, sports leagues and law enforcement agencies, but also the perfection of relevant law system of the copyright is inseparable from the media company to strengthen the marketing strategy of paying to watch, and more from the increasing enhancement of ordinary audience's copyright consciousness.

\section{CONCLUSIONS}

There is a symbiotic relationship between the sports game's copyright and sports new media. The development of sports new media is attached to the sports game's copyright, and the sports game cannot make its own value maximized away from the integration with media. It is an important explore on the way of sustainable development of sports industry to constantly dig copyright values of the upper resources and to deepen the coexistence and co-prosperity value construction of the game's copyright and sports media in order to make sports new media constantly optimize the mode of development and enhance their own strength.

\section{ACKNOWLEDGMENT}

This work has been supported by the Colleges and Universities Outstanding Youth and Middle Aged Scientific and Technological Innovation Team Project of Hubei Province (No.T201628) and the Science Research Foundation of Wuhan Business University (No.2015KA009).

\section{REFERENCES}

[1] J.H. Ran, "The esearch of the complementary development of sports TV media and new media in our country,” Sports Science, vol. 31, 2011, pp. 48-56.

[2] L. Luo, "Profitable innovation research on the representation of mass sports media,” Beijing sport university, 2013.

[3] G.Q. Guo, “Communication course,” Beijing: China Renmin university press, April 2011.

[4] H.W. Zhang, "Analysis of the present development situation and cause of national traditional sports in ordinary university," The Proceedings of the forums for the development of Chinese sports industry and sports goods industry, 2012, pp. 285-261.

[5] J.W. Kim, J.D. James, and Y.K. Kim, “A model of the relationship among sport consumer motives, spectator commitment, and behavioral intentions,” Journal of sport Management Review, 2013, pp. 173-185.

[6] D.S. Zhang and G.H. Zhang, "The study of the propagation mode of media sports," Sports science, vol. 36, 2016, pp. 3-9.

[7] W. Wei, "Direction and trend of the communication study in international sports in recent years,” Journal of sports science, vol. 5, 2016, pp. 10-17. 